\title{
Clinical Application of Near-Infrared Spectroscopy in Neonates
}

\section{Ga Won Jeon}

Department of Pediatrics, Inje University Busan Paik Hospital, Inje University College of Medicine, Busan, Korea

\section{ABSTRACT}

The incidence of cerebral palsy has not decreased despite advances in neonatal care. Preterm infants are at a high risk of cerebral palsy. Moreover, preterm infants might experience permanent neurological sequelae due to injury in the preterm brain. Although the etiology of preterm brain injury is not fully understood, preterm brain injury is strongly associated with abnormal cerebral perfusion and oxygenation. Monitoring systemic blood pressure or arterial oxygen saturation using pulse oximetry is not enough to guarantee proper cerebral perfusion or oxygenation. Early detection of improper cerebral perfusion can prevent irreversible cerebral damage. To decrease brain injury through the early detection of under-perfusion and deoxygenation, other diagnostic modalities are needed. Near-infrared spectroscopy can continuously and noninvasively monitor regional oxygen saturation $\left(\mathrm{rSO}_{2}\right)$, which reflects the perfusion and oxygenation status of tissues at bedside. Near-infrared spectroscopy represents a balance between tissue oxygen supply and demand. Cerebral $\mathrm{rSO}_{2}$ monitoring has been used most frequently in neonatal cardiac surgery to monitor cerebral oxygenation and prevent hypoxic damage or shock. Recently, cerebral, renal, or splanchnic $\mathrm{rSO}_{2}$ in neonates is frequently monitored. The progression of a disease, brain injury, and death can be prevented by detecting changes in $\mathrm{rSO}_{2}$ values using near-infrared spectroscopy. In this article, the basic principles, usefulness, and applications of near-infrared spectroscopy in neonates are discussed.

Key Words: Cerebrovascular circulation; Spectroscopy, near-infrared; Infant, newborn; Infant, premature; Splanchnic circulation

\section{INTRODUCTION}

Cerebral palsy occurs in 1 in 500 live births. Its incidence has not decreased despite advances in neonatal care ${ }^{1)}$. Preterm infants are at a high risk of cerebral palsy. It affects about $10 \%$ of very low birth weight preterm infants born in the United States. In addition, preterm infants might experience permanent neurological sequelae due to injury in the preterm brain $^{2)}$.

Although the etiology of preterm brain injury is not fully understood, it is known that
Received: 3 June 2019

Revised: 10 July 2019

Accepted: 17 July 2019

Correspondence to: Ga Won Jeon

Department of Pediatrics, Inje University Busan Paik Hospital, Inje University College of Medicine, 75 Bokji-ro, Busanjin-gu, Busan 47392, Korea

Tel: +82-51-890-6497

Fax: +82-51-895-7785

E-mail: iamgawon@paik.ac.kr https://orcid.org/0000-0002-8206-9727
Copyright(c)

By Korean Society of Neonatology. All right reserved.

This is an Open-Access article distributed under the terms of the Creative Commons Attribution Non-Commercial License (http://creativecommons.org/licenses/ by-nc/4.0), which permits unrestricted non-commercial use, distribution, and reproduction in any medium, provided the original work is properly cited. 
preterm brain injury is strongly associated with abnormal cerebral perfusion and oxygenation ${ }^{3)}$. Suboptimal cerebral oxygenation in preterm infants during the first 2 postnatal weeks is associated with poor neurodevelopmental outcome ${ }^{4)}$. Although a relationship between low arterial blood pressure and periventricular white matter injury has been reported ${ }^{5}$, monitoring systemic blood pressure or arterial oxygen saturation using pulse oximetry $\left(\mathrm{SpO}_{2}\right)$ is not enough to guarantee proper cerebral perfusion or oxygenation. This is because $\mathrm{SpO}_{2}$ only reflects arterial oxygen saturation $\left(\mathrm{SaO}_{2}\right)$, and not real oxygen saturation in deep tissues. Improper tissue perfusion and improper tissue oxygen delivery can be indirectly detected based on decreased $\mathrm{SaO}_{2}$, delayed capillary refill time, elevated blood lactate levels, metabolic acidosis, hypotension, or oliguria, according to their severity. However, these methods are non-specific. In addition, by the time caregivers detect these signs of improper tissue perfusion, it would be too late to recover from the tissue damage. Thus, early detection of improper tissue perfusion is needed to prevent irreversible tissue damage.

The brain is an autoregulatory organ. Thus, cerebral blood flow and pressure can be maintained within the normal range by itself, even when there are fluctuations in the systemic blood pressure. However, in severely ill infants and preterm infants with immature cerebral vascular tree, cerebral autoregulation ceases. Therefore, under-perfusion and deoxygenation may occur even if there are only slight fluctuations in the systemic blood pressure, which would result in hypoxic ischemic brain injury ${ }^{6}$. Decreasing brain injury through the early detection of under-perfusion and deoxygenation requires other diagnostic modalities.

Near-infrared spectroscopy (NIRS) is a noninvasive technique that can continuously monitor regional oxygen saturation $\left(\mathrm{rSO}_{2}\right)$, which reflects the perfusion status and oxygenation status of underlying tissues at the bedside ${ }^{7)}$. NIRS can detect improper tissue perfusion early, before irreversible cell or tissue damage occurs. NIRS predominantly measures the $\mathrm{rSO}_{2}$ of the venous blood, which is composed of a mixture of venous (75\%), arterial (20\%), and capillary (5\%) blood ${ }^{8)}$. NIRS represents tissue oxygen delivery and consumption. It reflects the balance between tissue oxygen supply and demand. Cerebral $\mathrm{rSO}_{2}$ monitoring has been frequently used in neonatal cardiac surgery to monitor cerebral perfusion and oxygenation and to prevent hypoxic damage or shock. Recently, cerebral, renal, or splanchnic $\mathrm{rSO}_{2}$ in neonates is frequently being monitored. NIRS is already used to monitor cerebral oxygenation in infants with hemodynamically significant ductus arteriosus (HSDA), cerebral oxygenation in infants with perioperative status of congenital heart disease, and splanchnic oxygenation in infants with necrotizing enterocolitis ${ }^{9}$. In this article, the underlying principles, usefulness, and applications of NIRS in the neonatal intensive care unit will be discussed.

\section{PRINCIPLES AND FUNCTIONS OF NIRS}

Near-infrared light (700 to $1,000 \mathrm{~nm}$ wavelength) can penetrate living tissues better than visible or ultraviolet light. The light absorption spectra are different between oxygenated and deoxyge nated hemoglobin ${ }^{10}$. Oxygenated hemoglobin can absorb more infrared light but less red light than deoxygenated hemoglobin. The NIRS device emits lights of two different wavelengths (730 and $810 \mathrm{~nm}$ ) from a light emitting diode. These emitted photons can pass through tissues and be absorbed by oxygenated and deoxygenated hemoglobin in living tissues at different ratios according to the oxygenation status of tissues (Figure 1). These photons from the light source can make arc. The non-absorbed fraction of the photons is received by two detectors. The proximal arc detector receives signal from superficial tissues whereas the distal arc detector receives signal from both superficial and deep tissues. The proximal value is subtracted from the distal value. The result represents the oxygen saturation at a depth of 1 to 2 $\mathrm{cm}$ in the deep tissue, which represents the $\mathrm{rSO}_{2}$ of the underlying tissue ${ }^{11)}$. The $\mathrm{rSO}_{2}$ is obtained using the following formula: $\mathrm{rSO}_{2}=$ [oxygenated hemoglobin/(oxygenated hemoglobin+deo-

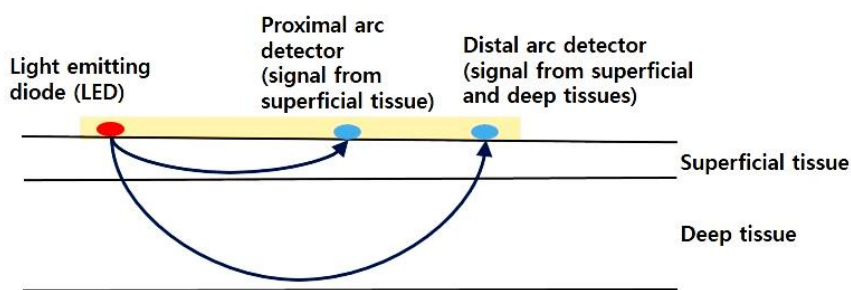

Figure 1. Principles of near-infrared spectroscopy. The nearinfrared spectroscopy device emits light from a light emitting diode. These emitted photons can pass through tissues and be come absorbed by oxygenated and deoxygenated hemoglobin in living tissues at different ratios according to the oxygenation status of tissues. These photons from the light source can make arc. The non-absorbed fraction of the photons is received by two detectors. The proximal arc detector receives signal from the superficial tissue whereas the distal arc detector receives signal from both the superficial and deep tissues. The proximal value is subtracted from the distal value and the result represents the oxygen saturation $\left(\mathrm{rSO}_{2}\right)$ at a depth of 1 to $2 \mathrm{~cm}$ in the deep tissue. 
xygenated hemoglobin)]. The fractional tissue oxygen extraction (FTOE) is the amount of oxygen extracted from tissues. It reflects the balance between oxygen supply and demand of the underlying tissue. The FTOE is obtained using the following formula: FTOE $=\left[\left(\mathrm{SaO}_{2}-\mathrm{rSO}_{2}\right) / \mathrm{SaO}_{2}\right]^{9)}$. A decrease in $\mathrm{rSO}_{2}$ indicates decreased blood flow, resulting in decreased oxygen delivery to the underlying tissue or increased oxygen extraction by the underlying tissue. Caregivers can check real time $\mathrm{rSO}_{2}$ in order to obtain prompt treatment, to guide interventions and to receive immediate response through specific interventions.

\section{CURRENT USE IN NEONATES}

In neonates, cerebral, renal, or splanchnic $\mathrm{rSO}_{2}$ is frequently monitored. Cerebral $\mathrm{rSO}_{2}$ is monitored to prevent brain damage in conditions which affect cerebral perfusion and oxygenation. These conditions include hypoxic ischemic encephalopathy, hypotension, apnea and bradycardia, HSDA, ductal closure, and perioperative status of congenital heart disease. Renal or splanchnic $\mathrm{rSO}_{2}$ is monitored to prevent renal or splanchnic underperfusion in infants with necrotizing enterocolitis and those with acute renal failure. Renal or splanchnic $\mathrm{rSO}_{2}$ is also monitored in infants to determine the need for red blood cell transfusion and to monitor response to red blood cell transfusion. There are a number of NIRS devices available for monitoring $\mathrm{rSO}_{2}$ in neonates. These NIRS devices include INVOS 5100 (Somanetics,
Troy, MI, USA), Fore-Sight (CAS Medical, Branford, CT, USA), SenSmart X-100 (Nonin Medical, Plymouth, MN, USA), Equanox 7600 (Nonin Medical, Plymouth, MN, USA), and NIRO-200NX (Hamamatsu Photonics, Hamamatsu, Japan), which are commonly used in neonatal intensive care units.

\section{Cerebral oxygenation at birth and hypoxic ischemic encephalopathy}

Cerebral $\mathrm{rSO}_{2}$ is usually lower than splanchnic or renal $\mathrm{rSO}_{2}$ because the metabolic activity of and demand for oxygen of the brain are higher than those of other living organs ${ }^{12)}$. Standard cerebral $\mathrm{rSO}_{2}$ is different according to different studies. It was reported to be $57 \%$ to $77 \%$ by McCormick et al. ${ }^{12)}, 62 \%$ to $78 \%$ by Lemmers et al. ${ }^{13)}, 56 \%$ to $76 \%$ by Petrova and Mehta ${ }^{14)}$, and $66 \%$ to $83 \%$ by McNeill et al. ${ }^{15)}$. Generally, the standard neonatal value of cerebral $\mathrm{rSO}_{2}$ is $60 \%$ to $80 \%$. Cerebral $\mathrm{rSO}_{2}$ baseline values are affected by altered blood flow due to arteriovenous malformations, superior sagittal sinus, or epidural hemorrhage, by extracranial structures, and by the placement of sensor on the forehead ${ }^{16,17)}$. Thus, evaluating the baseline value of cerebral $\mathrm{rSO}_{2}$ is important. After evaluating the baseline cerebral $\mathrm{rSO}_{2}$ value, we need to focus on its trend. Cerebral $\mathrm{rSO}_{2}$ is normally low for several minutes immediately after birth. It then increases ${ }^{18,19)}$ and becomes stable 7 minutes after birth ${ }^{20)}$. Pichler et al. ${ }^{21)}$ suggested reference ranges for the cerebral $\mathrm{rSO}_{2}$ and $\mathrm{FTOE}$ in neonates immediately after birth to prevent cerebral hyper- and hypooxygenation. They reported that the cerebral $\mathrm{rSO}_{2}$ is low at birth.
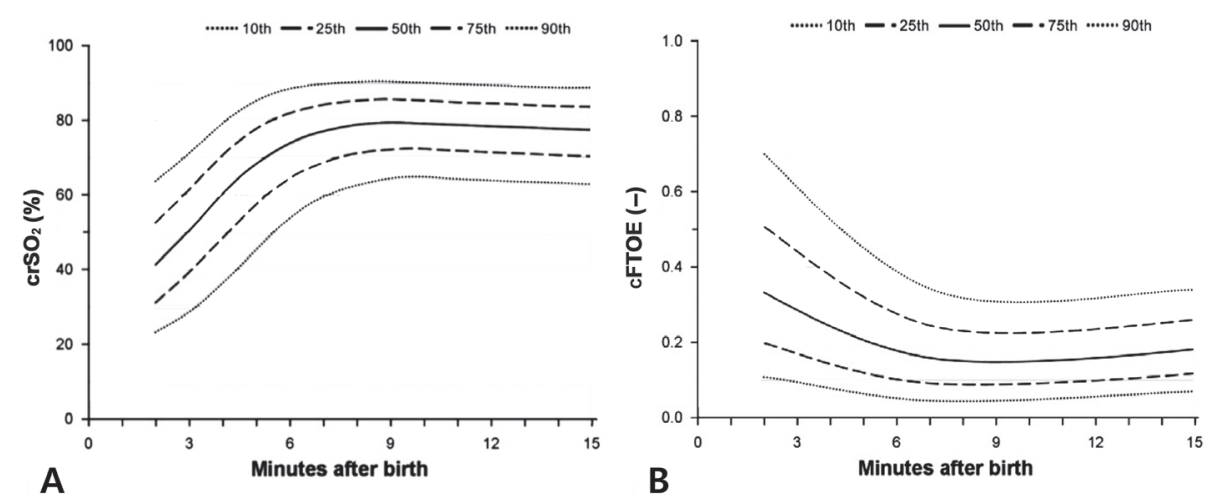

Figure 2. Cerebral regional oxygen saturation $\left(\mathrm{crSO}_{2}\right)$ and cerebral fractional tissue oxygen extraction (cFTOE) immediately after birth. (A) The 10th, 25th, 50th, 75th, and 90th percentiles of $\mathrm{CrSO}_{2}$ during the first 15 minutes after birth in neonates who do not require medical support. The $\mathrm{CrSO}_{2}$ is low at birth. It increases for several minutes and becomes stable. (B) The 10th, 25th, 50th, 75th, and 90th percentiles of cFTOE during the first 15 minutes after birth in neonates who do not require medical support. The cFTOE is high at birth. It decreases for several minutes and becomes stable. Adapted from Pichler et al. ${ }^{21)}$, with permission from Elsevier. 
It then increases for several minutes and becomes stable. On the contrary, the cerebral FTOE is high at birth. It then decreases for several minutes and becomes stable (Figure 2) ${ }^{21)}$. The cerebral $\mathrm{rSO}_{2}$ was decreased during immediate postnatal 15 minutes in preterm infants who needed $\mathrm{FiO}_{2}>0.3$ compared to that in preterm infants who needed $\mathrm{FiO}_{2} \leq 0.3^{11)}$. This suggests that in some preterm infants, oxygen has to be supplied liberally, not restrictively, to decrease early postnatal hypoxia. On the contrary, Sorensen and Greisen ${ }^{22)}$ reported that healthy preterm infants have lower FTOE and higher cerebral $\mathrm{rSO}_{2}$ with elevated blood $\mathrm{pCO}_{2}$, meaning higher cerebral oxygenation, compared to term infants. They concluded that prematurity itself is not more prone to cerebral hypoxia than term.

Neonates with hypoxic ischemic encephalopathy have in creased cerebral $\mathrm{rSO}_{2}$ and decreased cerebral FTOE ${ }^{23)}$. This means that cerebral perfusion is increased with improper cerebral autoregulation, while cerebral oxygen consumption is decreased with secondary energy failure during hypoxic ischemic encephalopathy ${ }^{24)}$. Among infants with hypoxic ischemic encephalopathy, those with poor neurodevelopmental outcomes have higher initial cerebral $\mathrm{rSO}_{2}$ than those with better neurodevelopmental outcomes ${ }^{23)}$. Infants with hypoxic ischemic brain injury identified using brain magnetic resonance imaging have higher initial cerebral $\mathrm{rSO}_{2}$ than those without hypoxic ischemic brain injury $^{25)}$.

\section{Cerebral oxygenation in preterm infants}

Preterm infants have different cerebral $\mathrm{rSO}_{2}$ baselines at immediate postnatal stage according to gestational age. Preterm infants have increased cerebral $\mathrm{rSO}_{2}$ and decreased cerebral FTOE compared to term infants at birth. The younger the gestational age, the higher the cerebral $\mathrm{rSO}_{2}$ and the lower the cerebral $\mathrm{FTOE}^{26,27)}$. Cerebral $\mathrm{rSO}_{2}$ decreases while cerebral FTOE increases according to gestational age at birth, reaching the nadir of $\mathrm{rSO}_{2}$ and the peak of the FTOE at a gestational age between 38 and 39 weeks ${ }^{28)}$. Cerebral $\mathrm{rSO}_{2}$ also decreases as preterm infants mature, reaching the nadir between 6 and 8 postnatal weeks ${ }^{28)}$.

Variations in the cerebral blood flow according to the cerebral perfusion pressure is limited by cerebral autoregulation. Preterm infants are at a high risk of impaired cerebral autoregulation mainly due to immaturity of the cerebral vessels. It has been reported that impaired cerebral autoregulation in preterm infants is highly associated with neonatal death ${ }^{29)}$. Caregivers can assess cerebral blood flow and perfusion pressure by measuring cerebral
$\mathrm{rSO}_{2}$ using the NIRS in order to quickly identify impaired cerebral autoregulation. Cerebral $\mathrm{rSO}_{2}$ monitoring may help in the early diagnosis of impaired cerebral autoregulation and prevent irreversible brain injury or death ${ }^{30)}$.

\section{Cerebral oxygenation in preterm infants with patent ductus arteriosus}

Decreased cerebral oxygenation due to HSDA adversely influences brain growth and neurodevelopmental outcome ${ }^{31)}$. Ductus arteriosus requiring surgical ligation was associated with lowest cerebral $\mathrm{rSO}_{2}$ before closure $\left(\mathrm{rScO}_{2}<40 \%\right)$ and brain damage in preterm infants ${ }^{31)}$. Preterm infants with HSDA generally have lower cerebral $\mathrm{rSO}_{2}$ but higher cerebral FTOE compared to preterm infants without HSDA ${ }^{32)}$. Furthermore, these values are normalized after closure of the HSDA ${ }^{32)}$. However, the interpretation of cerebral $\mathrm{rSO}_{2}$ values in relation to ductus arteriosus remains controversial. Schwarz et al. ${ }^{33)}$ found higher cerebral FTOE ( $0.43 \pm 0.05$ vs. $0.38 \pm 0.05, P=0.038)$ but no difference in cerebral $\mathrm{rSO}_{2}(54 \% \pm 5 \%$ vs. $58 \% \pm 5 \%, P=0.102)$ when they compared preterm infants with HSDA to those without HSDA.

There are still controversies about the effect of the closure of ductus arteriosus on cerebral blood flow and cerebral oxygen de livery. Indomethacin decreases cerebral blood flow and cerebral oxygen delivery whereas ibuprofen does not alter cerebral blood flow or cerebral oxygen delivery ${ }^{34)}$. Underwood et al. ${ }^{35)}$ also reported that cerebral $\mathrm{rSO}_{2}$ is decreased whereas somatic $\mathrm{rSO}_{2}$ is increased after the administration of indomethacin. Huning et al. $^{36)}$ reported that cerebral oxygenation does not change, although cerebral blood flow immediately after ligation of the ductus arteriosus shows a brief increase. On the contrary, Lemmers et al. ${ }^{37)}$ reported that cerebral $\mathrm{rSO}_{2}$ is decreased immediately after ligation of the ductus arteriosus. Vanderhaegen et al. ${ }^{38)}$ showed that cerebral $\mathrm{rSO}_{2}$ is increased while cerebral FTOE is decreased during ligation of the ductus arteriosus but returns to baseline following ligation. This suggests that ligation of the ductus arteriosus does not adversely influence cerebral oxygenation.

\section{Cerebral oxygenation in infants with perioperative status of congenital heart disease}

NIRS has been used most frequently for the perioperative monitoring of cerebral oxygenation during neonatal cardiac surgery to prevent hypoxic damage or shock. The decrease in cerebral $\mathrm{rSO}_{2}$ detected using NIRS during operation to treat congenital 
heart disease is frequent because cardiopulmonary bypass can cause an abrupt change in cerebral blood flow and oxygenation. Therefore, cerebral $\mathrm{rSO}_{2}$ monitoring is required during cardiac surgery to monitor cerebral oxygenation and to prevent hypoxic damage ${ }^{39)}$. Hansen et al. ${ }^{40)}$ reported that decreased cerebral $\mathrm{rSO}_{2}$ after cardiac surgery might be related to redistribution of blood flow from cerebral circulation to somatic circulation. It has been suggested that increased cerebral vascular resistance and pharmacological afterload reduction can cause redistribution of blood flow from cerebral circulation to somatic circulation, eventually resulting in decreased oxygen delivery to the brain. Low cerebral $\mathrm{rSO}_{2}(<56 \%)$ detected using NIRS, during the first 48 postoperative hours, is associated with subsequent poor outcome such as death, need for extracorporeal membrane oxygenation, or longer hospitalization in the intensive care unit ${ }^{41)}$. Hence, monitoring of cerebral oxygenation is highly recommended to promptly identify patients at risk of poor outcome since poor outcome can be prevented by improving cerebral oxygenation.

\section{Splanchnic oxygenation in infants with necrotizing enterocolitis}

Splanchnic $\mathrm{rSO}_{2}$ is usually higher than cerebral $\mathrm{rSO}_{2}$ due to higher metabolic activity in the brain. McNeill et al. ${ }^{15)}$ reported that splanchnic $\mathrm{rSO}_{2}$ is $5 \%$ to $15 \%$ higher than cerebral $\mathrm{rSO}_{2}$ while Patel et al. ${ }^{42)}$ reported that the splanchnic $\mathrm{rSO}_{2}$ in preterm infants without necrotizing enterocolitis is $63 \%$ to $91 \%$.

Necrotizing enterocolitis is one of the most common gastrointestinal morbidities in preterm infants. The pathogenesis of necrotizing enterocolitis is multifactorial. However, intestinal ischemia is known to precede necrotizing enterocolitis. Preterm infants without necrotizing enterocolitis have higher splanchnic $\mathrm{rSO}_{2}$ during the first week of life compared to preterm infants who develop necrotizing enterocolitis later $(77.3 \%$ vs. $70.7 \%$, $P=0.002)^{42)}$. Preterm infants with splanchnic $\mathrm{rSO}_{2} \leq 56 \%$ are at 11 times increased risk of developing necrotizing enterocolitis compared to preterm infants with splanchnic $\mathrm{rSO}_{2}>56 \%{ }^{42)}$. Low splanchnic $\mathrm{rSO}_{2}$ and high splanchnic FTOE in preterm infants are associated with complicated necrotizing enterocolitis, impending bowel perforation, or death compared to preterm infants with uncomplicated necrotizing enterocolitis ${ }^{43)}$. Thus, NIRS monitoring is required to differentiate preterm infants who would subsequently develop complicated necrotizing enterocolitis from those who would not. Splanchnic $\mathrm{rSO}_{2}$ monitoring may contribute to the early diagnosis of necrotizing enterocolitis and prevent bowel perforation or death.

\section{CONCLUSION}

NIRS has been widely used in neonatal intensive care units in Korea by the Korean National Health Insurance since 2018. Health insurance coverage for the somatic $\mathrm{rSO}_{2}$ of high risk neonates in the neonatal intensive care unit includes the following: (1) re spiratory distress syndrome requiring ventilator care; (2) HSDA or complex heart disease; (3) shock or sepsis; and (4) hypoxic ischemic encephalopathy according to notification no. 2018-184 of the Ministry of Health and Welfare in September 2018.

NIRS can be used for continuous monitoring noninvasively at the bedside without interrupting the routine care of caregivers. Reference ranges of $\mathrm{rSO}_{2}$ and FTOE are different in different infants. They are also different according to postnatal days even in the same infant. Their values are affected by a lot of variables that can affect the oxygen demand and consumption of tissues, such as the metabolic activity of tissues, fever or hypothermia, perfusion status, blood pressure, and level of hemoglobin, espe cially in preterm infants with anemia. Specifically, splanchnic $\mathrm{rSO}_{2}$ (infra-umbilical) is affected by sensor position, bladder distension, or urinary catheter. Thus, the interpretation of $\mathrm{rSO}_{2}$ values or FTOE values is controversial, and there are no universally accepted normal values. These limitations of NIRS could be the main obstacle to introduce NIRS as a routine bedside mo nitoring for neonates. However, there are advantages of NIRS monitoring. Caregivers need to focus on the baseline values and trends of changes in these values to prevent the progression of the disease, brain injury, or death. Further studies with a large number of neonates are required to reach a consensus on the uniform interpretation of the values and to develop universally accepted normal values.

\section{CONFLICT OF INTEREST}

No potential conflict of interest relevant to this article was reported. 


\section{REFERENCES}

1. Novak I, Morgan C, Adde L, Blackman J, Boyd RN, BrunstromHernandez J, et al. Early, accurate diagnosis and early intervention in cerebral palsy: advances in diagnosis and treatment. JAMA Pediatr 2017;171:897-907.

2. Babcock MA, Kostova FV, Ferriero DM, Johnston MV, Brunstrom JE, Hagberg H, et al. Injury to the preterm brain and cerebral palsy: clinical aspects, molecular mechanisms, unanswered questions, and future research directions. J Child Neurol 2009; 24:1064-84.

3. Van Bel F, Van de Bor M, Stijnen T, Baan J, Ruys JH. Aetiological role of cerebral blood-flow alterations in development and extension of peri-intraventricular haemorrhage. Dev Med Child Neurol 1987;29:601-14.

4. Verhagen EA, Van Braeckel KN, van der Veere CN, Groen H, Dijk PH, Hulzebos CV, et al. Cerebral oxygenation is associated with neurodevelopmental outcome of preterm children at age 2 to 3 years. Dev Med Child Neurol 2015;57:449-55.

5. Børch K, Lou HC, Greisen G. Cerebral white matter blood flow and arterial blood pressure in preterm infants. Acta Paediat 2010;99:1489-92.

6. Wong FY, Silas R, Hew S, Samarasinghe T, Walker AM. Cerebral oxygenation is highly sensitive to blood pressure variability in sick preterm infants. PLoS One 2012;7:e43165.

7. Marin T, Moore J. Understanding near-infrared spectroscopy. Adv Neonatal Care 2011;11:382-8.

8. Watzman HM, Kurth CD, Montenegro LM, Rome J, Steven JM, Nicolson SC. Arterial and venous contributions to near-infrared cerebral oximetry. Anesthesiology 2000;93:947-53.

9. Sood BG, McLaughlin K, Cortez J. Near-infrared spectroscopy: applications in neonates. Semin Fetal Neonatal Med 2015;20: 164-72.

10. Grometto A, Pizzo B, Strozzi MC, Gazzolo F, Gazzolo D. Cerebral NIRS patterns in late preterm and very preterm infants becoming late preterm. J Matern Fetal Neonatal Med 2019;32:1124-9.

11. Garvey AA, Dempsey EM. Applications of near infrared spectroscopy in the neonate. Curr Opin Pediatr 2018;30:209-15.

12. McCormick PW, Stewart M, Goetting MG, Dujovny M, Lewis G, Ausman JI. Noninvasive cerebral optical spectroscopy for monitoring cerebral oxygen delivery and hemodynamics. Crit Care Med 1991;19:89-97.

13. Lemmers PM, Toet M, van Schelven LJ, van Bel F. Cerebral oxygenation and cerebral oxygen extraction in the preterm infant: the impact of respiratory distress syndrome. Exp Brain Res 2006; 173:458-67.

14. Petrova A, Mehta R. Near-infrared spectroscopy in the detection of regional tissue oxygenation during hypoxic events in preterm infants undergoing critical care. Pediatr Crit Care Med 2006;7:
449-54.

15. McNeill S, Gatenby JC, McElroy S, Engelhardt B. Normal cerebral, renal and abdominal regional oxygen saturations using nearinfrared spectroscopy in preterm infants. J Perinatol 2011;31:517.

16. Sorensen LC, Leung TS, Greisen G. Comparison of cerebral oxygen saturation in premature infants by near-infrared spatially resolved spectroscopy: observations on probe-dependent bias. J Biomed Opt 2008;13:064013.

17. Kishi K, Kawaguchi M, Yoshitani K, Nagahata T, Furuya H. In fluence of patient variables and sensor location on regional cerebral oxygen saturation measured by INVOS 4100 near-infrared spectrophotometers. J Neurosurg Anesthesiol 2003;15:302-6.

18. Schwaberger B, Pichler G, Binder-Heschl C, Baik N, Avian A, Urlesberger B. Transitional changes in cerebral blood volume at birth. Neonatology 2015;108:253-8.

19. Kenosi M, O'Toole JM, Livingston V, Hawkes GA, Boylan GB, O'Halloran KD, et al. Effects of fractional inspired oxygen on cerebral oxygenation in preterm infants following delivery. J Pediatr 2015; 167:1007-12.

20. van Vonderen JJ, Roest AA, Siew ML, Walther FJ, Hooper SB, te Pas AB. Measuring physiological changes during the transition to life after birth. Neonatology 2014;105:230-42.

21. Pichler G, Binder C, Avian A, Beckenbach E, Schmolzer GM, Urlesberger B. Reference ranges for regional cerebral tissue oxygen saturation and fractional oxygen extraction in neonates during immediate transition after birth. J Pediatr 2013;163:155863.

22. Sorensen LC, Greisen G. The brains of very preterm newborns in clinically stable condition may be hyperoxygenated. Pediatrics 2009;124:e958-63.

23. Toet MC, Lemmers PM. Brain monitoring in neonates. Early Hum Dev 2009;85:77-84.

24. Toet MC, Lemmers PM, van Schelven LJ, van Bel F. Cerebral oxygenation and electrical activity after birth asphyxia: their relation to outcome. Pediatrics 2006;117:333-9.

25. Wintermark P, Hansen A, Warfield SK, Dukhovny D, Soul JS. Near-infrared spectroscopy versus magnetic resonance imaging to study brain perfusion in newborns with hypoxic-ischemic encephalopathy treated with hypothermia. Neuroimage 2014; 85 Pt 1:287-93.

26. Alderliesten T, Dix L, Baerts W, Caicedo A, van Huffel S, Naulaers $G$, et al. Reference values of regional cerebral oxygen saturation during the first 3 days of life in preterm neonates. Pediatr Res 2016;79:55-64.

27. Pellicer A, Greisen G, Benders M, Claris O, Dempsey E, Fumagalli $\mathrm{M}$, et al. The SafeBoosC phase II randomised clinical trial: a treatment guideline for targeted near-infrared-derived cerebral tissue oxygenation versus standard treatment in extremely pre- 
term infants. Neonatology 2013;104:171-8.

28. Tina LG, Frigiola A, Abella R, Artale B, Puleo G, D'Angelo S, et al. Near infrared spectroscopy in healthy preterm and term new. borns: correlation with gestational age and standard monitoring parameters. Curr Neurovasc Res 2009;6:148-54.

29. Wong FY, Leung TS, Austin T, Wilkinson M, Meek JH, Wyatt JS, et al. Impaired autoregulation in preterm infants identified by using spatially resolved spectroscopy. Pediatrics 2008;121:e60411.

30. Riera J, Cabanas F, Serrano JJ, Madero R, Pellicer A. New developments in cerebral blood flow autoregulation analysis in pre term infants: a mechanistic approach. Pediatr Res 2016;79:460 5.

31. Lemmers PM, Benders MJ, D'Ascenzo R, Zethof J, Alderliesten T, Kersbergen KJ, et al. Patent ductus arteriosus and brain volume. Pediatrics 2016;137:e20153090.

32. Lemmers PM, Toet MC, van Bel F. Impact of patent ductus arteriosus and subsequent therapy with indomethacin on cerebral oxygenation in preterm infants. Pediatrics 2008;121:142-7.

33. Schwarz CE, Preusche A, Wolf M, Poets CF, Franz AR. Prospective observational study on assessing the hemodynamic relevance of patent ductus arteriosus with frequency domain near-infrared spectroscopy. BMC Pediatr 2018;18:66.

34. Patel J, Roberts I, Azzopardi D, Hamilton P, Edwards AD. Randomized double-blind controlled trial comparing the effects of ibuprofen with indomethacin on cerebral hemodynamics in preterm infants with patent ductus arteriosus. Pediatr Res 2000; 47:36-42.

35. Underwood MA, Milstein JM, Sherman MP. Near-infrared spectroscopy as a screening tool for patent ductus arteriosus in extremely low birth weight infants. Neonatology 2007;91:134-9.
36. Huning BM, Asfour B, Konig S, Hess N, Roll C. Cerebral blood volume changes during closure by surgery of patent ductus arteriosus. Arch Dis Child Fetal Neonatal Ed 2008;93:F261-4.

37. Lemmers PM, Molenschot MC, Evens J, Toet MC, van Bel F. Is cerebral oxygen supply compromised in preterm infants undergoing surgical closure for patent ductus arteriosus? Arch Dis Child Fetal Neonatal Ed 2010;95:F429-34.

38. Vanderhaegen J, De Smet D, Meyns B, Van De Velde M, Van Huffel S, Naulaers G. Surgical closure of the patent ductus arteriosus and its effect on the cerebral tissue oxygenation. Acta Paediatr 2008;97:1640-4.

39. Uebing A, Furck AK, Hansen JH, Nufer E, Scheewe J, Dutschke $\mathrm{P}$, et al. Perioperative cerebral and somatic oxygenation in neonates with hypoplastic left heart syndrome or transposition of the great arteries. J Thorac Cardiovasc Surg 2011;142:523-30.

40. Hansen JH, Schlangen J, Voges I, Jung O, Wegmann A, Scheewe J, et al. Impact of afterload reduction strategies on regional tissue oxygenation after the Norwood procedure for hypoplastic left heart syndrome. Eur J Cardiothorac Surg 2014;45:e13-9.

41. Phelps HM, Mahle WT, Kim D, Simsic JM, Kirshbom PM, Kanter $\mathrm{KR}$, et al. Postoperative cerebral oxygenation in hypoplastic left heart syndrome after the Norwood procedure. Ann Thorac Surg 2009;87:1490-4.

42. Patel AK, Lazar DA, Burrin DG, Smith EO, Magliaro TJ, StarkAR, et al. Abdominal near-infrared spectroscopy measurements are lower in preterm infants at risk for necrotizing enterocolitis. Pediatr Crit Care Med 2014;15:735-41.

43. Schat TE, Schurink M, van der Laan ME, Hulscher JB, Hulzebos $\mathrm{CV}$, Bos AF, et al. Near-infrared spectroscopy to predict the course of necrotizing enterocolitis. PLoS One 2016;11:e0154710. 